\title{
Asia and the Middle Pleistocene in \\ Global Perspective
}

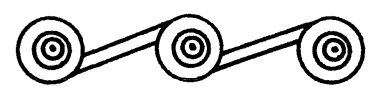

LYNNE A. SCHEPARTZ AND SARI MILLER-ANTONIO

DiffERENCES AMONG THE ASIAN, AFricAn, AND EUROPEAN PREHISTORIC records are well documented by assemblages that illustrate technological variability and diverse subsistence strategies. Until recently these differences were interpreted without detailed knowledge of Asian paleoenvironments. In addition, early Pleistocene hominid expansions from Africa into regions of Asia, once thought to have taken place no earlier than one million years ago, are now unquestionably much older. Not only did these movements greatly enlarge the human territory, but they also exposed humans to the vast array of resources they still exploit today. Hominid encounters with Asian environments involved the continued exploitation of grasslands and also offered the challenge of adaptation to uplands, colder regions, and sub-tropical zones-a pattern that became widespread during the Middle Pleistocene (787-127 kya, corresponding to Oxygen Isotope Stages 19-6). These topics were the focus of a conference and discussions held in 2001 at the East-West Center in Honolulu (see Miller-Antonio et al. [2001] for more details on the conference). Selected papers from that meeting are collected in this volume, and serve as a forum for exchange between parts of the world that have long been studied in relative isolation. Figure 1 presents a regional map of localities discussed in these papers.

To provide historical background for Paleolithic research in Asia, the volume begins with a tribute to Jia Lanpo, a scholar whose work was critical in the establishment of Asian prehistory and who played a major role in the debates on the archaeological relationship between Asia and the West. The highly integrative nature of his work made the Chinese prehistoric record accessible to scholars worldwide. This tribute is followed by an interview with one of China's foremost archaeologists and Jia's student, Huang Weiwen. It is a retrospective on the development of prehistoric research in China, and an examination of the similarities and differences among archaeological perspectives and approaches in other Asian countries.

The next three papers examine Asia from a broad perspective, discussing the

Lynne A. Schepartz is with the Department of Anthropology at the University of Cincinnati, Ohio; Sari Miller-Antonio is with the Department of Anthropology/Geography at California State University, Stanislaus.

Asian Perspectives, Vol. 43, No. 2 (C) 2004 by the University of Hawai'i Press. 


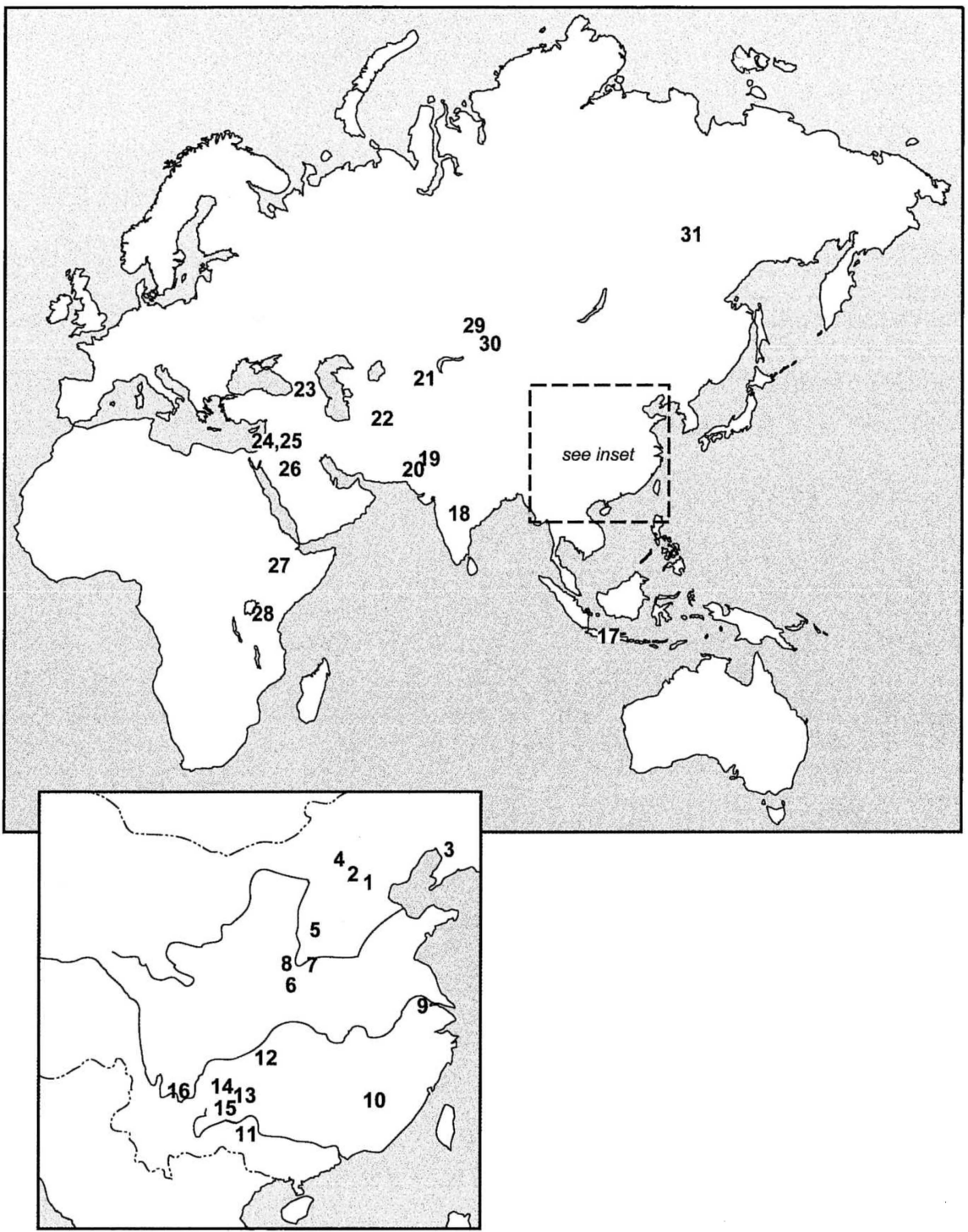

Fig. 1. Map of localities examined in this volume. 1. Zhoukoudian; 2. Nihewan Basin sites (Cenjiawan, Maliang, Xiaochangliang, Donggutuo); 3. Jinniushan; 4. Xüjiayao; 5. Dingcun; 6. Luonan Basin sites; 7. Sanmenxia; 8. Gongwangling; 9. Hexian; 10. Maba; 11. Bose Basin sites; 12. Tongzi; 13. Guanyindong; 14. Shuicheng; 15. Panxian Dadong; 16. Yuanmou; 17. Sangiran; 18. Bori; 19. Riwat; 20. Dina; 21. Kuldara; 22. Kashafrud; 23. Dmanisi; 24. Gesher Benot Ya'acov; 25. 'Ubeidiya; 26. 'Ain Nefud; 27. Koobi Fora; 28. Olduvai; 29. Denisova, Okladnikov Caves; 30. KaraBom; 31. Diring Yuriakh.

impact of climate change and the opening of new environmental niches. Dennell synthesizes the latest information on paleoclimates linked to the uplift of the Himalayas and the formation of the Asian monsoon pattern. He identifies two key trends in hominid dispersals. The first is that earliest movements into southern Asia involved use of the grassland niche familiar to African hominids. $\mathrm{He}$ 
correlates the first appearance of Acheulean assemblages in Southwest and South Asia with increasingly arid conditions in the Lower Pleistocene. Slightly later in time, bifacial assemblages characterize early sites in southern China. A second trend, apparent in the late Lower Pleistocene, involved the expansion into colder environments and the use of non-Acheulean, simple core and flake (Mode 1) tools.

Keates provides an overview of hominid home range size in Middle Pleistocene China using data on raw material source distance. She then examines how faunal dispersals (most notably Equus) and water availability affect hominid expansions into colder climates. She also uses arguments based on hominid morphology to support the idea of interaction and sustained migrations between eastern Asian and Eurasian populations.

One key component of adaptations to colder Eurasian environments was undoubtedly the ability to use and control fire. Rolland presents the evidence for fire production and home bases as major hominid innovations and critically examines the arguments for these behaviors at Zhoukoudian from the perspective of contemporaneous behavior in Eurasia and Africa. He documents the co-occurrence of fire use with cave occupations, and provides a model for the integration of fire and home bases into hominid culture-based adaptations.

The next group of papers deals with current research on northern and southern Chinese sites. In their paper on two Nihewan Basin localities, Chen and Wei take a synthetic approach to lithic analysis that includes refitting, low-power use-wear studies, and a careful examination of core reduction strategies. They describe a technological regime that included knapping skill and planned use of raw material. Their results document a greater degree of technological variability in northern Chinese lithic assemblages than previously identified.

The prehistory of southern China is represented by a set of related papers on Panxian Dadong Cave, one of the few southern Middle Pleistocene sites with a series of chronometric dates. The contribution by Wang et al. provides the geological context for the site. The stratigraphic sequence and climatic changes documented in the Dadong Cave deposits are also compared with the QinghaiTibet Plateau glacial and interglacial sequences. Miller-Antonio et al. contribute a techno-economic analysis of the Dadong lithics. They examine the selective use of lithic raw material in order to evaluate hominid behavioral strategies of resource management. Much of the information about Middle Pleistocene paleoenvironment and adaptations to the mountainous Guizhou landscape comes from detailed analyses of the Dadong faunal assemblage and other, comparable faunas, as presented in Bekken et al. Data on faunal composition and density are used to develop an understanding of the environmental context and the adaptive range required of hominid populations not only at Dadong, but also within the region. Together, the Dadong papers provide specific information on the site while placing it within the context of regional, upland exploitation.

\section{ACKNOWLEDGMENTS}

Funding and sponsorship for the conference Asia and the Middle Pleistocene in Global Perspective were provided by the Henry Luce Foundation, the Wenner-Gren Foundation for Anthropological Research, and the East-West Center and the Bishop Museum in Honolulu. In addition, the Henry Luce and Wenner-Gren foundations 
supported the production of this volume. The task of compiling and producing this special volume of Asian Perspectives would not have been possible without the assistance and support of the editor, Miriam Stark, and the highly capable staff headed by Joshua Bauer. We are grateful to be able to present these papers in a manner that makes them available to the diverse Asian Perspectives readership.

\section{REFERENCE CITED}

Miller-Antonio, Sari, Lynne A. Schepartz, and Deborah Bakken

2001 New directions in paleolithic archaeology: Asia in the Middle Pleistocene in global perspective. Current Anthropology 42(5): 747-749. 